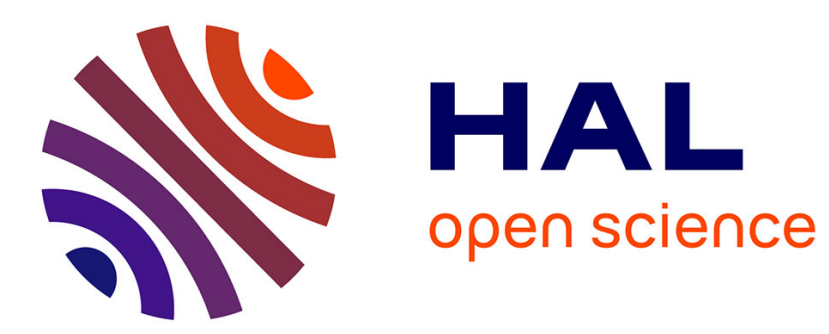

\title{
The role of social costs as a mechanism enforcing the honesty of ultraviolet-reflecting signals in a lizard
}

\author{
Anna Kawamoto, Jean-François Le Galliard, Arnaud Badiane
}

\section{To cite this version:}

Anna Kawamoto, Jean-François Le Galliard, Arnaud Badiane. The role of social costs as a mechanism enforcing the honesty of ultraviolet-reflecting signals in a lizard. Biological Journal of the Linnean Society, 2021, 133 (4), pp.1126-1138. 10.1093/biolinnean/blab008 . hal-03376443

HAL Id: hal-03376443

https://cnrs.hal.science/hal-03376443

Submitted on 13 Oct 2021

HAL is a multi-disciplinary open access archive for the deposit and dissemination of scientific research documents, whether they are published or not. The documents may come from teaching and research institutions in France or abroad, or from public or private research centers.
L'archive ouverte pluridisciplinaire HAL, est destinée au dépôt et à la diffusion de documents scientifiques de niveau recherche, publiés ou non, émanant des établissements d'enseignement et de recherche français ou étrangers, des laboratoires publics ou privés. 
1 The role of social costs as a mechanism enforcing the honesty of ultraviolet signals in a

2 lizard

3 Anna Kawamoto*1, Jean-François Le Galliard ${ }^{1,2}$, Arnaud Badiane*1

4

$5 \quad{ }^{1}$ Sorbonne Université, CNRS, IRD, INRA, Institut d'écologie et des sciences de

6 l'environnement (IEES), 4 Place Jussieu, 75005 Paris, France.

$7 \quad{ }^{2}$ Centre de recherche en écologie expérimentale et prédictive (CEREEP-Ecotron

8 IleDeFrance), Département de biologie, Ecole Normale Supérieure, CNRS, PSL Research

9 University, UMS 3194, 11 chemin de Busseau, 77140 Saint-Pierre-lès-Nemours, France

10

$11 *$ Both authors contributed equally to this work

12

13 Corresponding author: Anna Kawamoto - annakaw423@gmail.com

14

15 Short title: Social costs of an ultraviolet signal

16 


\section{Abstract}

20 According to animal signalling theory, social costs, for example induced by aggression from

21 conspecifics, are one of the mechanisms maintaining signal honesty. While our understanding

22 of signal evolution has much improved for pigment-based colours, the mechanisms

23 maintaining the honesty of structural colour signals, such as ultraviolet (UV), remain elusive.

24 Here, we used the common lizard Zootoca vivipara to test whether the honesty of UV signals

25 displayed on male throats is under social control. To do so, we staged dyadic agonistic

26 interactions between non-manipulated focal males and opponents of either larger or smaller

27 body size. We used either control or manipulated UV signals to create small cheaters with

28 UV-enhanced throats, large cheaters with UV-reduced throats, and their respective controls.

29 In support of a conventional signal hypothesis, focal males were aggressive towards large

30 cheaters and became submissive when these large cheaters retaliated, and were less

31 submissive against small cheaters. However, that focal males were not more aggressive

32 towards small cheaters contradicts our initial predictions. We then confirmed that male UV

33 coloration and bite force were good predictors of contest outcomes in control conditions.

34 Overall, we provide partial evidence suggesting that social costs enforce UV signal honesty in 35 common lizards.

36

37 Key words: Animal communication - Deception - Male competition - Ultraviolet - Zootoca

38 vivipara

39

40 


\section{Introduction}

Animals use an astounding variety of signals to communicate with one another and these signals constitute the backbone of animal social interactions. To be evolutionarily stable, signals must confer net fitness benefits to both senders and receivers and this condition can be achieved only if signals are honest on average (Maynard Smith \& Harper, 2003; Searcy \& Nowicki, 2005; Bradbury \& Vehrencamp, 2011). When the interests of senders and receivers diverge, mechanisms enforcing signal honesty are required to prevent low-quality individuals from dishonestly signalling high quality (Searcy \& Nowicki, 2005). For example, differential costs conditional on the sender's quality may be associated with the signal to ensure its honesty (Searcy \& Nowicki, 2005; Bradbury \& Vehrencamp, 2011; Higham, 2014). These costs may be a direct consequence of signal production and/or maintenance (i.e. physiological costs, Zahavi, 1975; Grafen, 1990; Higham, 2014; Webster, Ligon, \& Leighton, 2018), or may be imposed by receivers, for example in the form of retaliation or punishment during social interactions (i.e. social costs, Johnstone \& Norris, 1993; Guilford \& Dawkins, 1995; Bradbury \& Vehrencamp, 2011; Bachmann et al., 2017).

Conventional signals, sometimes referred to as badges of status in the context of male competition, fall in the second category (Hurd, 1997; Whiting, Nagy, \& Bateman, 2003; Bradbury \& Vehrencamp, 2011). They are linked to the advertised quality based on an arbitrary convention (Guilford \& Dawkins, 1995; Hurd \& Enquist, 2005) and are often associated with socially imposed costs during agonistic interactions (Higham, 2014; Weaver,

Koch, \& Hill, 2017). Tibbetts (2014) and Webster et al. (2018) further highlight that physiological and social costs need not be mutually exclusive in maintaining honest signalling and argue that, regardless of whether physiological costs exist or not, social costs are likely to arise during aggressive interactions. This is because receivers are more likely to attack when rivals have similar signalling level as their own (Tibbetts, 2014), and/or when they discern a 
67 mismatch between their opponent's quality and signalling level (Rohwer \& Rohwer, 1978). In both cases, cheating becomes particularly costly for low-quality individuals because of the increased risk of injury due to physical attacks (Tibbetts, 2014). In spite of this, most studies investigating honest signalling focused on physiological costs and very few on social costs, thus leading Bachmann et al. (2017) to call for adequately designed studies to reduce this research bias.

Colour signals constitute a diverse class of signals and result from different colourproducing mechanisms including pigmentary and structural components (Shawkey \& D'Alba, 2017). Recent evidence has much improved our understanding of the signalling role and evolution of pigment-based colours such as melanin- and carotenoid-based colours (Svensson \& Wong, 2011; Roulin, 2016; Weaver et al., 2017; San-Jose \& Roulin, 2018). In fact, most conventional signals described so far are colour signals (but see Molles \& Vehrencamp, 2001; Vehrencamp, 2001) displayed during male-male competition that involve pigment-based colours, especially melanin-based black or white coloration (Møller, 1987; Martín \& Forsman, 1997; Qvarnstrom, 1997; Beani \& Turillazzi, 1999; Ligon \& McGraw, 2016; Bachmann et al., 2017). Social costs can also maintain the honesty of rapid colour change (Ligon \& McGraw, 2016), and of pigment-based colours potentially costly to produce (Martín \& Forsman, 1997).

The costs maintaining the honesty of structural colour signals, including ultraviolet (UV) signals, are yet to be uncovered. Some lines of argument suggest that assembling the dermal, light-scattering nanoscale structures composing structural coloration could pose developmental challenges, which could ultimately maintain signal honesty but robust evidence is still lacking (Fitzpatrick, 1998; Kemp \& Rutowski, 2007; Kemp, Herberstein, \& Grether, 2012; Kemp \& Grether, 2015; White, 2020). UV signals have also been suggested to function as conventional signals especially in lizards, but hard proof is still needed to confirm 
this hypothesis (Whiting et al., 2003; Stapley \& Whiting, 2006). Names et al. (2019) manipulated the UV-blue patches of male common wall lizards (Podarcis muralis) during male agonistic contests. They found that males were less aggressive and more submissive against cheaters than against honest males, thus rejecting a conventional signal hypothesis in this species. In blue tits (Cyanistes caeruleus), three important studies suggested that the UV coloration displayed on male crowns may function as conventional signals during male contests (Alonso-Alvarez et al., 2004; Poesel et al., 2007; Rémy et al., 2010). These, however, are not conclusive since they were designed to explore the role of UV signals during agonistic interactions rather than to test whether social costs enforced their honesty.

To identify social costs of colour signals, researchers must experimentally create out-ofequilibrium colour signals to simulate cheating individuals and examine whether these cheaters receive more aggression than honest signallers during agonistic interactions (Ligon \& McGraw, 2016; Bachmann et al., 2017; Names et al., 2019). In this study, we used the common lizard Zootoca vivipara to investigate whether or not socially imposed costs maintain the honesty of UV signals. Male common lizards display UV-reflecting signals on their throat (Martin et al., 2013) that play a role during male-male competition (Martin et al., 2016) and female mate choice (Badiane et al., 2020). In addition, UV chroma on male throat increases with age and body size (Bonnaffé et al., 2018). Altogether, these results strongly suggest that male UV-reflecting throats might signal male quality in Z. vivipara. Furthermore, body size is one of the best predictors of male contest outcome in lizards with larger lizards more likely to win fights than smaller ones (Carpenter, 1995; Fitze \& Le Galliard, 2008; Names et al., 2019). Body size is thus a cue widely used by lizards to extract information on male quality (we use the terms 'signal' and 'cue' as defined in Bradbury \& Vehrencamp, 2011). 
Here, we first determined whether or not male-induced social costs are associated with

117 dishonest UV signals in this species, and then investigated the relative importance of male UV

118 signals, bite force and body size during male agonistic contests. To do so, we designed dyadic

119 agonistic encounters between non-manipulated focal males and opponents that were either

120 smaller or larger than focal males, with either a control (i.e. honest) or a manipulated (i.e.

121 cheaters) UV-reflecting throat. To disrupt the correlation between UV signal and quality, we

122 used lizards of different body size. Our rational was that precise quality traits advertised by

123 UV signals are not completely known yet in this species, but body size is a well-known cue of

124 male quality that correlates with UV signals in this and other lizards species (Bonnaffé et al.,

125 2018). Specifically, small opponents were either UV-control or UV-enhanced so as to create

126 cheaters of lower quality (i.e. small) with high signalling level. Large opponents were either

127 UV-control or UV-reduced so as to create cheaters of higher quality (i.e. large) with a low

128 signalling level. If the UV-reflecting throat functions as socially enforced conventional

129 signals, we predict that cheaters will pay the cost of their dishonesty in the form of received

130 aggression from focal males. We thus expected focal males to behave more aggressively and

131 be less submissive against cheaters than against honest opponents.

132 Material and Methods

133 Study species

134 The common lizard (Zootoca vivipara) is a small lacertid inhabiting humid habitats across

135 Eurasia (Massot et al., 1992). In our study site, adult males usually emerge from hibernation

136 in March. The emergence of females starts approximately 3-4 weeks later in the beginning of

137 April, depending on weather conditions, and marks the beginning of the mating season

138 (Massot et al., 1992). During the mating season, males chase away other males to ensure

139 access to females and there is endurance competition among males to find mates (Heulin,

140 1988). Adult common lizards occupy overlapping home-ranges and are polygynandrous, with 
141 both sexes having multiple sexual partners (Laloi et al., 2004; Fitze et al., 2005). Adult males

142 have a conspicuous belly ranging from yellow to red, interspersed with numerous black spots

143 (Martin et al., 2013; San-Jose et al., 2017). In females, ventral coloration is duller, from

144 cream to orange, with fewer black spots than males and extends more on the throat (Bauwens,

145 1987; Cote et al., 2008). In addition, the ventral and throat coloration have a secondary

146 reflectance peak in the UV, which is especially pronounced in males, particularly on their

147 throat (Martin et al., 2013).

148 Sampling and measurements

149 On March $19^{\text {th }} 2019$, we captured 59 adult males by hand at the Centre de Recherche en

150 Ecologie Expérimentale et Prédictive (CEREEP-Ecotron Ile-De-France, $48^{\circ} 17^{\prime} \mathrm{N}, 2^{\circ} 41^{`} \mathrm{E}$ ),

151 where a captive population of common lizards is maintained in separate $100-\mathrm{m}^{2}$ enclosures

152 under natural, outdoor environmental conditions. We brought the lizards to the laboratory,

153 measured their snout-vent length (SVL) with a ruler $( \pm 1 \mathrm{~mm})$, and their body mass using a

154 digital scale $( \pm 1 \mathrm{mg})$. We also measured bite force, which provides a good proxy for fighting

155 ability and whole-organism performance in lizards (Huyghe et al., 2005; Lappin \& Husak,

156 2005). To do so, we used a purpose-built bite force meter constructed from a modified Sauter

$15725 \mathrm{~N}$ digital force gauge. We retained the maximum score out of three bite force

158 measurements and made sure that the lizards had a body temperature comprised between

$15930^{\circ} \mathrm{C}$ and $35^{\circ} \mathrm{C}$ when biting (Lappin \& Jones, 2014), since their preferred body temperature is

160 around $32-34^{\circ} \mathrm{C}$ (Rozen-Rechels et al., 2020).

161 We obtained reflectance spectra from the throat and belly of each male (two replicates

162 per body region) using a USB-2000 diode-array spectrophotometer with a R400-7-UV/VIS

163 reading-illumination probe (Ocean Optics Inc.) and a notebook computer running OceanView

164 (Ocean Optics Inc.). We took reflectance readings in a darkened room using an HL-2000

165 Halogen-Deuterium light source (Ocean Optics Inc.) for full spectrum illumination. We 
166 recorded reflectance spectra relative to a white diffuse standard (WS1; Ocean Optics Inc.) and

167 a dark reading. We set integration time to 9 , scans to average to 10 , and boxcar width to 10 .

168 For data acquisition, we hand-held the probe over the centre of the targeted colour patch with

169 a $90^{\circ}$ angle between the probe and the skin surface (i.e. coincident normal recording

170 geometry, Anderson \& Prager, 2006). An entomological pin attached to the tip of the probe

171 allowed us to maintain a constant distance of $3 \mathrm{~mm}$ between the tip of the probe and the skin

172 surface. We always aimed the probe at a skin area larger than $1.5 \mathrm{~mm}$ in diameter that did not

173 contain any black spot to avoid spectral contamination (Badiane et al., 2017). We later

174 processed spectral data in R v.3.3.2 (R Development Core Team, 2017) using the package

175 pavo 2.0 (Maia et al., 2019). We cropped each spectrum between $300-700 \mathrm{~nm}$, smoothed

176 them using a loess smooth span of 0.2 , and averaged the two replicates recorded for each

177 body region. Then, we extracted two UV-related colorimetric variables from the throat

178 spectra, namely spectral intensity (i.e. $\mathrm{R}_{300-700}$ ), and UV chroma (i.e. $\mathrm{R}_{300-400} / \mathrm{R}_{300-700}$ ).

179 Following measurement, we placed the lizards individually in opaque terraria

$180(25 \times 15.5 \times 15 \mathrm{~cm})$ layered with soil substrate, and equipped with a shelter $(7,6 \times 15,2 \times 15,1$

$181 \mathrm{~cm}$, ExoTerra) and a small water dish (Petri dish $\sim 5 \mathrm{~cm}$ in diameter). An incandescent bulb

$182(25 \mathrm{~W})$ and white light UV-B neon tubes (Reptisun 10.0 UVB, Zoomed) provided heat and

183 light following a 10/14-h dark-light schedule. We provided food three times a week (300-400

$184 \mathrm{mg}$ of live house crickets, Acheta domesticus) and water ad libitum. Lizards were housed for a

185 total of 18 days, including 10 days of acclimation to the laboratory conditions during which

186 we waited the lizards' first moult to occur as it marks the onset of sexual activity (Laloi et al.,

187 2011), and 8 days of experiment.

188 Colour manipulation and behavioural assays

189 Behavioural assays took place in a temperature-controlled room maintained at $21^{\circ} \mathrm{C}$ using two

190 neutral arenas to eliminate any resident-intruder effect (Martin et al., 2015, 2016). Arenas 
191 were composed of a large opaque plastic terrarium $(75 \times 50 \times 40 \mathrm{~cm})$ with one transparent wall to allow video recording, and contained a layer of blond peat as substrate. Two removable opaque plastic walls divided the arena into two equally-sized compartments on both sides and a larger compartment at the centre. The two compartments at the extremities of the arena served as solitary holding areas to allow acclimation to the neutral arena, and were each equipped with a $25-\mathrm{W}$ heat bulb placed $15 \mathrm{~cm}$ above a shelter (Exoterra Inc.) that also acted as basking spot. In the central compartment, we placed another $30-\mathrm{W}$ heat bulb $15 \mathrm{~cm}$ above a wooden basking spot $(12 \times 8 \times 1.5 \mathrm{~cm})$. We illuminated the arenas with a light-emitting plasma fixture (Gavita Pro 270 $\mathrm{e}$ GROW LEP) placed $80 \mathrm{~cm}$ above the bottom of the arena. This light source reproduces almost exactly the full spectrum of the sun, including UVB and UVA thanks to a UV transmitting glass filter, and is thus ideal to examine the role of UV signals during laboratory experiments. White, opaque curtains surrounded the two arenas at a 1-m distance to create visual isolation. Two digital SLR cameras (Nikon D500 and Nikon D5300) mounted on tripods recorded the experiments in high definition from a lateral, slightly elevated point of view, through the transparent wall of the arena.

To test the hypothesis that male-induced social costs are associated with dishonest UV signals in common lizards, we staged dyadic encounters using 59 adult male common lizards $(\mathrm{SVL}$, range $=50-63$, mean $=57$; body mass, range $=2.4-5.3$, mean $=3.8)$. Each dyadic interaction was unique and involved medium-sized (56-60 $\mathrm{mm}$ in SVL), non-manipulated focal males $(n=29)$, which faced opponents of either larger $(n=15)$ or smaller size $(n=15)$ with control or manipulated throat UV reflectance. Small opponents ranged from 50-55 mm in SVL and were either UV-control or UV-enhanced. Large opponents (60-63 mm in SVL), in contrast, were either UV-control or UV-reduced. This study design allowed us to create a mismatch between UV signalling level and body size, and ultimately with male quality since body size is a primary predictor of fighting ability and male contest outcome in lizards 
216 (Carpenter, 1995; Karsten et al., 2009; Baird, 2013; Names et al., 2019). Focal males were 217 always 3-6 mm larger $(\beta=4.21 \mathrm{~mm} \pm 0.41, \mathrm{p}<0.001)$ and $1-5 \mathrm{~mm}$ smaller $(\beta=-2.84 \mathrm{~mm} \pm$ $0.42, \mathrm{p}<0.001)$ than their small and large opponents, respectively. There were no significant differences in body size and body mass between small controls and small cheaters (SVL: $\beta=-$ $0.38 \mathrm{~mm} \pm 0.66, \mathrm{p}=0.978$; body mass: $\beta=-0.21 \mathrm{~mm} \pm 0.21, \mathrm{p}=0.846)$, nor between large controls and large cheaters (SVL: $\beta=0.30 \pm 0.68, p=0.991$; body mass: $\beta=0.37 \pm 0.22, p=$ $0.465)$

To reduce the UV reflectance within the natural range of variation, we used UVblocking (290-400 nm) inorganic agents (zinc oxide and titanium dioxide) mixed with a fat combination of petroleum jelly and liquid paraffin (respectively, 6:4:50:40 for $100 \mathrm{~g}$ ). Large males of the control group were treated with the fat combination and large males of the UVreduced treatment were treated with the fat combination mixed with the inorganic agents (Figure 1). The spectral curve of this UV-reduction corresponded well with the spectra obtained in previous studies (Martin et al., 2016; Badiane et al., 2020). We applied both mixtures using a thin paintbrush on the lizards' throat, from the tip of the jaw to the collar scale row. To enhance throat UV reflectance, we used a light orange Edding 4500 T-shirt marker pen (colour code 016) that reflects in the UV range. This marker is similar to those previously used to enhance UV-blue coloration in birds and lizards (Kurvers et al., 2010; Rémy et al., 2010; Names et al., 2019), except that we used light orange instead of light blue in our study because it better matches the natural throat colour of male common lizards. To facilitate the marker application on the lizards' throat, we dismantled the marker and pressed the ink reservoir so as to deposit a drop of water-based ink on a plate, then we dipped the tip of a forceps into the droplet and spread it on the lizards' throat from the tip of the jaw to the collar scale row. We then let it dry for a few minutes before starting the experiments. Small lizards from the UV-enhanced group were treated with this marker pen while small lizards 
241 from the UV-control group were not treated at all (Figure 1). As Figure 1 illustrates, our UV-

242 enhancing treatment augmented throat reflectance in UV but also in the orange part of the

243 spectrum, and spectral shape looked somewhat artificial. This marker pen, however, produced

244 the best spectral shape of all the different marker pens and paintings we have tried.

245 Each focal male participated in four dyadic encounters against four different males from

246 the four treatments (i.e. small cheaters, small controls, large cheaters, and large controls)

247 presented in a random sequence. We chose the opponent so as to standardize the size

248 difference between focal and opponent males, such that the largest focal males encountered

249 the largest opponents from both the small and large size categories, and the smallest focal

250 males faced the smallest opponents of both size categories. We designed the experiment such

251 that focal males participated to encounters only once every two days, and opponents not more

252 than once a day. We performed a total of 116 trials during 8 days with a maximum of 16 trials

253 per day ( 8 trials per arena per day) during the activity period of the lizards from 09:00 to

254 17:00. Most males from the paired interactions had no prior knowledge of each other because

255 they were hosted in separate enclosures during all their lives, except for 14 tests (12\%) for

256 which both males came from the same $100-\mathrm{m}^{2}$ enclosure. However, in 12 out of these 14

257 encounters, both males were entering their first reproductive season (almost 2 years old) and

258 had therefore not competed in the past. The two remaining contests both involved a sexually

259 mature male (almost 3 years old) against a newly sexually mature male (almost 2 years old),

260 and had therefore never competed against each other. In the light of this, it is unlikely that

261 prior knowledge due to sexual competition among the males impacted our results.

Before each experiment, we removed the participating males from their home terrarium,

263 manipulated their throat coloration, and randomly placed each male in one of the two

264 compartments of the neutral arena. We allowed a first 10-min acclimation period with the

265 shelters and basking spot in both compartments. After 10 min, we removed the shelters from 
266 the compartments and allowed another 10-min acclimation period without shelters to force

267 them to be active, leaving the heat bulb turned on for thermoregulation. After this 20 -min

268 acclimation period with and without shelters (and without observers), the experiment started

269 as we removed the opaque walls to reveal the central area and immediately turned the heat

270 bulbs from the two compartments off, such that the only basking spot left is the wooden plate

271 at the centre of the arena. We turned the video camera on and left the room to prevent any

272 observer-induced disturbance. The experiment lasted $20 \mathrm{~min}$ as the two males behaved and

273 competed for the basking spot. Next, a single observer, blind to the experimental treatments,

274 used Jwatcher (Blumstein \& Daniel, 2007) to analyse the lizards' behaviours from all the

275 video recordings to avoid any observer effect.

276 We recorded each time a lizard performed any of the behaviours described in Table 1

277 (Martin et al., 2016; Names et al., 2019). We assigned a coefficient to each of these

278 behaviours to give more weight to the most aggressive behaviours, since they are more likely

279 to be costly for the opponent (Carazo, Font, \& Desfilis, 2008; Abalos et al., 2016). Although

280 an obvious hierarchy exists between behaviours with regard to contest escalation, there still is

281 some degree to which coefficient assignment can be subjective and arbitrary. Hence, in

282 addition to the first set of coefficients we consider as most relevant, we assigned two more

283 sets of coefficients to examine how coefficient assignment may influence our results. We thus

284 calculated three versions of the aggression score and three versions of the submission score as

285 indicated in Table 1. In addition, we recorded basking duration, that is the time spent basking

286 on the wooden plate, because males competed over a unique basking spot. We also recorded

287 the duration of wall-scratching behaviour for each male. This behaviour consists of males

288 scratching the walls of the arena to try to escape and may be due to stress as a consequence of

289 laboratory conditions (de Fraipont 2000, Rozen-Rechels 2018). It may also be triggered by a 
290 male fleeing from another male. None of the contests resulted in observable injuries and all

291 males were released to their semi-natural outdoor enclosures after the 8 days of experiment.

\section{Statistical analyses}

293 We used R v.3.3.2 (R Development Core Team, 2017) to perform two complementary set of

294 statistical analyses of the behavioural data.

295 Social costs on dishonest UV signals

296 First, to test whether or not social costs are imposed on dishonest male UV signals, we

297 calculated two categorical variables named 'opponent size' with two levels ('large' and

298 'small') and named 'opponent honesty' with two levels ('honest' and 'cheaters'). Honest

299 males corresponded to UV-control males while cheaters corresponded to manipulated males

300 from both the UV-reduced and UV-enhanced treatment groups. Then, we ran LMMs for

301 Gaussian variables and GLMMs for Poisson variables using the following response variables

302 for focal males: the three versions of aggression score, the three versions of submission score,

303 basking duration, and duration of wall-scratching behaviour. We included male ID and trial

304 order as random intercepts in these models. We considered trial order as random because we

305 were not interested in the effects of trial order per se; however, we also ran these models with

306 trial order as fixed factor and present the results from post-hoc Tukey tests when significant.

307 We included the additive effects of opponent size and opponent honesty as well as their two-

308 way interactions, and the additive effect of bite force as fixed effects. When the interaction

309 was significant, we split our data set according to the "opponent size" category to explore the

310 interaction. To reduce the impact of influential values (detected with Cook's distances) and

311 improve our models, we performed an alpha-winsorisation with a 0.03 trim on the submission

312 score and wall-scratching behaviour. For all the models described above, we checked the

313 model assumptions using the performance R package (Lüdecke et al., 2020). We used a

314 squared-root transformation for wall-scratching behaviour to comply with these assumptions. 
315 All continuous variables assuming a Gaussian distribution were centred and scaled prior to

316 analyses to ease result interpretations (Schielzeth, 2010).

317 Determinants of male contests

318 Next, to explore the role of body size, bite force, and throat UV reflectance during male

319 agonistic contests, we analysed only interactions between focal males and control opponents

320 from both size categories, thus excluding the cheaters. We used linear mixed-effects models

321 (LMMs) and generalized linear mixed-effects models (GLMMs) to test the additive effects of

322 bite force, UV chroma, spectral intensity, opponent body size, opponent UV chroma, and

323 opponent spectral intensity on the three versions of aggression score, the three versions of

324 submission score, basking duration, and duration of wall-scratching behaviour. We included

325 the same random intercepts as above. We used the lme4 R package (Bates et al., 2015) to

326 perform GLMMs on count variables assuming a negative binomial distribution for the

327 aggression score and a Poisson distribution for the submission score. For the remaining

328 response variables (i.e. basking duration, and wall-scratching duration), we assumed a

329 Gaussian distribution and used LMMs as implemented in the nlme R package (Pinheiro et al.,

330 2019). To reduce the impact of influential values (detected with Cook's distances) and

331 improve our models, we performed an alpha-winsorisation with a 0.03 trim on the submission

332 score and wall-scratching behaviour. We proceeded with a model selection and conditional

333 averaging procedure as implemented in the MuMin R package (Bartoń, 2019), using the

334 functions dredge and model.avg. This model selection procedure allowed us to select the best

335 models $(\triangle \mathrm{AICc}<2)$ from all possible combinations of predictors, including a null model

336 without any predictor.

337 Results

338 Social costs on dishonest UV signals 
339 We found that the two-way interaction between opponent size and opponent honesty

340 influenced significantly the aggression score of focal males $(\beta=-0.33 \pm 0.12, p=0.005)$. In

341 conflicts with smaller males, opponent honesty did not significantly explain the aggression

342 score of focal males, though the tendency was a smaller aggression score of focal males (UV-

343 enhanced cheaters: $\beta=-0.15 \pm 0.09, p=0.075)$. In conflicts with larger males, focal males

344 were significantly more aggressive (by 1.2 units on average) towards UV-reduced cheaters

345 than towards honest opponents $(\beta=0.18 \pm 0.08, \mathrm{p}=0.021$, Figure $2 \mathrm{~A})$. When the two

346 alternative versions of the aggression score were used, the results were qualitatively similar.

347 Furthermore, our analyses revealed that the two-way interaction between opponent size

348 and opponent honesty best explained the submission score of focal males $(\beta=-0.73 \pm 0.16, p$

$349<0.001$ ). More precisely, focal males were less submissive (by 1.4 units of submission score

350 on average) against small cheaters (UV-enhanced) than against small honest males $(\beta=-0.33$

$351 \pm 0.13, \mathrm{p}=0.012$ ), but more submissive (by 1.7 units on average) against large cheaters (UV-

352 reduced) than against large honest males $(\beta=0.50 \pm 0.11, \mathrm{p}<0.001$; Figure $2 \mathrm{~B})$. When the

353 two alternative versions of the submission score were used, results were qualitatively similar

354 except that we did not find that focal males were less submissive against small cheaters (UV-

355 enhanced).

356 Moreover, treatment factors did significantly explain the time focal males spent at the

357 basking spot, nor the time spent performing wall-scratching behaviours. Statistics are fully

358 reported in Supp. Info. S1. When we included trial order as fixed instead of random factor, all

359 the above results were qualitatively similar, and we found that aggression ratio was lower

360 during the second trial than during the first $(\beta=-0.24 \pm 0.08, p=0.025)$ and the third $(\beta=-$

$3610.26 \pm 0.09, \mathrm{p}=0.013)$.

362 Determinants of male contests in control interactions 
363 In control interactions, males with a higher aggression score (calculated with the first set of

364 coefficients) had a significantly higher bite force $(\beta=0.29 \pm 0.11, p=0.010)$. This result was

365 corroborated when we used both alternative aggression scores. In addition, focal males were

366 more submissive (submission score calculated with the first set of coefficients) against

367 opponents with a high throat spectral intensity $(\beta=0.28 \pm 0.12, p=0.023)$. When we used the

368 two alternative versions of the aggression score, however, none of the predictors were

369 significant. We also found that males with a higher bite force tended to spend more time on

370 the basking spot than males with lower bite force $(\beta=0.31 \pm 0.16, p=0.059)$. Focal males

371 spending more time performing wall-scratching behaviours had higher throat spectral

372 intensity $(\beta=0.47 \pm 0.17, p=0.006)$. Statistics are fully reported in Supp. Info. S2. When we

373 included trial order as fixed instead of random factor, all the above results were qualitatively

374 similar, and we found that the submission score was lower during the third trial than during

375 the first $(\beta=-0.55 \pm 0.19, p=0.017)$, the second $(\beta=-0.92 \pm 0.25, p=0.002)$, and the fourth

$376 \operatorname{trial}(\beta=-1.19 \pm 0.27, \mathrm{p}<0.001)$

377 Discussion

378 Our results revealed partial evidence that socially imposed costs may enforce the honesty of

379 UV-reflecting signals in male common lizards Z. vivipara. In support of the hypothesis of

380 social costs, focal males were more aggressive against large UV-reduced cheaters than against

381 large honest opponents, and were less submissive against small UV-enhanced cheaters than

382 against small honest opponents. However, inconsistently with this hypothesis, focal males

383 were not more aggressive against small UV enhanced cheaters than against small honest

384 opponents and were more submissive against large UV-reduced cheaters than against large

385 honest opponents. In addition to this, our analyses excluding manipulated males indicated that

386 male bite force is an important predictor of male contest outcome.

387 Social costs on dishonest UV signals 
388 We provide partial evidence that the UV components of the UV-reflecting throat of common 389 lizards may function as conventional signals enforced by male-induced social costs. The story 390 becomes more complex than expected when we examine the aggression and submission 391 scores. On one hand, large males with UV-reduced throats received more aggressions but also 392 triggered more submissive behaviours in focal males. This result suggests that, for large 393 males, downplaying UV signals is costlier than being honest since these large UV-reduced 394 cheaters are more likely to be challenged by the smaller focal males. When the focal males 395 challenge the large cheaters, the latter may retaliate since, after all, they are larger and more 396 likely to win fights, and focal males end up being more submissive. Hence, under this 397 scenario, what seemed to be a contradictory result at first glance may in fact be coherent and 398 support the idea that UV signals function as conventional signals in this species. Although 399 large males pose a serious threat to smaller males, if a large male signals low condition, it 400 may pay-off for smaller males to challenge this large male and gain a fitness advantage (e.g. 401 access to resources and/or females). Unexpectedly, small UV-enhanced cheaters did not 402 receive more aggression from the focal males compared to their honest counterparts.

403 However, that focal males behaved less submissively against small cheaters aligns with the 404 predictions of a conventional signal hypothesis.

405 In the case of conventional signals, social costs are either imposed to individuals that 406 signal above a given threshold intensity or penalize the mismatch between the sender's quality 407 or behaviour and its signalling level. Signal honesty can therefore be maintained only if these 408 costs exceed the benefits of cheating (Searcy \& Nowicki, 2005; Bradbury \& Vehrencamp, 409 2011). However, some degree of deception may still arise and pay off as long as the signal 410 remains honest to some degree (Adams \& Mesterton-Gibbons, 1995; Carazo \& Font, 2014).

411 Individuals can either be exclusively honest or exclusively dishonest, or switch from one 412 strategy to another according to the situation they find themselves into, depending on whether 
413 the signal is very labile and can change rapidly or not (Akçay, Campbell, \& Beecher, 2013;

414 Wilson \& Angilletta, 2015; Ligon \& McGraw, 2016). In common lizards, the UV-reflecting

415 coloration on males' throat does not seem to change rapidly (Bonnaffé et al., 2018), thus

416 leaving little room for "occasional" cheating. Retaliation or punishment rules taking the form

417 of physical and non-physical aggressions are the main mechanisms maintaining the honesty of

418 conventional signals (Martín \& Forsman, 1997; Tibbetts \& Izzo, 2010; Tibbetts, 2014;

419 Wilson \& Angilletta, 2015; Ligon \& McGraw, 2016). In this regard, the different behaviours

420 measured in our study do not have the same weight as evidence of socially imposed costs. Our

421 aggression score is the most meaningful factor here because it is the most likely to inflict a

422 cost (e.g. injury) on the opponent. Overall, social costs taking the form of physical aggression

423 may be quite high in common lizards, as $43 \%$ of our staged encounters (50 out of 116 )

424 escalated to the point of a male biting another male at least once. Although we cannot

425 estimate the cost-benefit balance of cheating in our study, the risk of injury due to physical

426 aggression is high and should not be neglected in this species (Le Galliard et al., 2005). On

427 top of this, other behavioural processes, for instance in the form of non-physical aggression

428 and/or spatial dominance, not necessarily measured, may increase the impact of social costs.

429 Our submission score may therefore capture the reaction to such behaviours and give us hints

430 on whether or not social costs exist. Altogether, our results seem to indicate that cheating is

431 generally more costly than being honest, although it is not always clear-cut.

432 In fact, the inconsistencies in our results involved almost exclusively interactions

433 between focal males and small opponents, as small UV-enhanced cheaters did not receive

434 more aggression from focal males. A possible interpretation may simply be that cheating is

435 more likely to pay off for a small male that exaggerates its UV signal than for a large male

436 that downplays its signal. However, in the context of male-male competition, we would

437 expect social costs to prevent low-quality males from signalling high quality, and gain 
438 advantage in terms of resources and/or access to females over males that are actually of higher 439 quality (e.g. Molles \& Vehrencamp, 2001). Another hypothesis may be that smaller males 440 generally behave in a non-threatening way when they face larger males, for example by 441 avoiding being close to larger opponent. Therefore, focal males would not need to show any 442 sign of aggression and spatial occupancy, perhaps captured in our submission score, may be 443 enough to affirm dominance. Alternatively, if focal males are more aggressive towards any 444 opponent that signals above a given threshold intensity, and that small honest males are 445 already signalling close to or above that threshold, we would not see any difference in terms 446 of aggression score between small UV-enhanced cheaters and their honest counterparts. 447 However, in this context, we would not expect to find differences in the submission 448 score as we did here. This also raises the possibility that our results were obscured by our UV 449 manipulation protocol. While the experimental reduction of the UV reflectance within the 450 natural range of variation has been previously validated in the common lizard (Martin et al., 451 2016; Badiane et al., 2020) and other lizard species (Martin et al., 2015; Names et al., 2019), 452 it is much more difficult to enhance UV reflectance. To the best of our knowledge, only a 453 handful of studies have experimentally augmented the UV coloration of animals, mostly in 454 the blue tit Cyanistes caeruleus (Poesel et al., 2007; Rémy et al., 2010) and one study in the 455 common wall lizard Podarcis muralis (Names et al., 2019). In these and our study, whether or 456 not these UV-enhanced patches can be considered to be within the natural range of variation 457 remains debatable, since spectral shape can look artificial. In addition, our marker pen did not 458 only increase reflectance in the UV range but also in the orange part of the spectrum (idem, to 459 a lesser extent, with the UV reduction treatment) and this may set a limit to results' 460 interpretations since we do not know how this may have influenced the outcome of our 461 behavioural experiments. It is therefore possible that the focal males did not consider the UV462 enhanced throat of small cheaters as a high signalling level, but simply as an 'odd' signal. For 
example, the increased orange coloration on the throat may somewhat resemble female's throats (Martin et al., 2013) and thus confuse the receivers. In addition, we cannot exclude that the artificial light orange colour faded to some extent during the experiment, although not completely (pers. obs.). Future studies should investigate adequate methods to enhance "naturally" UV coloration so that research on UV signalling may take a step forward.

\section{Determinants of male contests}

To further explore the individual determinants of male contests, we focused exclusively on encounters between focal and honest males. We found that aggression score correlated positively with male bite force, thus providing evidence that bite force is a good proxy of male dominance. Bite force has been previously linked with male dominance (Husak et al., 2006), male mating success (Lappin \& Husak, 2005), and male fighting capacity (Huyghe et al., 2005) in lizards. Moreover, our results revealed that focal males were more submissive against opponents with high throat intensity on one hand, but focal males with high throat intensity spent more time performing wall-scratching behaviour on the other. It may seem contradictory if we interpret wall-scratching behaviour as a submissive behaviour, which could well be the case, but it could also be linked with individual stress unrelated to the opponent behaviour (de Fraipont et al., 2000; Rozen-Rechels et al., 2018). Nevertheless, the results from this first part of the analyses were somewhat sensitive to the different set of coefficients used to calculate the aggression and submission scores. Hence, the robustness of these results is somewhat challenged, and this should lead behavioural ecologists and ethologists to take the effects of weighted behaviours into account when behavioural scores are calculated.

\section{Conclusion}

Overall, our study highlights that UV coloration of male throat plays a role during male contests, both from the point of view of the signaller, as it correlates with the signaller's 
488 behaviour, and from the perspective of the receiver since receivers adjust their behaviour 489 based on these signals. Therefore, our study confirms the importance of UV coloration as 490 predictors of male contest outcomes in the common lizard (Martin et al., 2016). However, we 491 can only provide partial evidence that social costs maintain the honesty of UV-reflecting

492 signals. This is because we observed different patterns of physical and non-physical

493 aggression in the face of deception in situations where focal males faced small opponents than 494 with large opponents. Although not entirely conclusive, this suggests that UV signals can be 495 honest thanks to context-dependent social costs imposed by rival males during male-male 496 competition. Future work should keep investigating these avenues of signal honesty with UV 497 signals to improve our understanding of animal communication at large.

498 Research data

499 All data used in this study will be made freely available on the public repository Zenodo.

\section{Acknowledgements}

501 We are thankful to Bruno Malhao for helping us build the two experimental arenas and Simon 502 Chollet for lending the plasma lamps. This study is part of the project UVSIGNAL funded by 503 a Marie Sklodowska-Curie fellowship (European program Horizon 2020) attributed to Arnaud 504 Badiane. This work has benefited from technical and human resources provided by CEREEP505 Ecotron IleDeFrance (CNRS/ENS UMS 3194) as well as financial support from the Regional 506 Council of Ile-de-France under the DIM Program R2DS bearing the reference I-05-098/R. It 507 has received a support under the program" Investissements d'Avenir" launched by the French 508 government and implemented by ANR with the reference ANR-11-INBS-0001 AnaEE France 509 and ANR-10-IDEX-0001-02 PSL. The capture, handling, and experimentation on the animals 510 in this study was authorized by the Ministère de l'Enseignement Supérieur, de la Recherche et 511 de l'Innovation (ref. APAFIS\#19642-2019030616456029v4), and by the Direction

512 départementale de la protection des populations (ref. 2017-01666). 


\section{References}

514 Abalos J, Pérez i de Lanuza G, Carazo P \& Font E. 2016. The role of male coloration in

515 the outcome of staged contests in the European common wall lizard (Podarcis muralis).

516 Behaviour 153: 607-631.

517 Adams ES \& Mesterton-Gibbons M. 1995. The cost of threat displays and the stability of

518 deceptive communication. Journal of Theoretical Biology 175: 405-421.

519 Akçay Ç, Campbell SE \& Beecher MD. 2013. Individual differences affect honest

520 signalling in a songbird. Proceedings of the Royal Society B: Biological Sciences 281.

Alonso-Alvarez C, Bertrand S, Devevey G, Gaillard M, Prost J, Faivre B \& Sorci G.

2004. An experimental test of the dose-dependent effect of carotenoids and immune activation

523 on sexual signals and antioxidant activity. American Naturalist 164: 651-659.

524 Anderson S \& Prager M. 2006. Quantifying colors. In: Hill GE, Mcgraw KJ, eds. Bird

525 coloration: Volume 1, mechanisms and measurements., 41-89.

Bachmann JC, Cortesi F, Hall MD, Marshall NJ, Salzburger W \& Gante HF. 2017.

527 Real-time social selection maintains honesty of a dynamic visual signal in cooperative fish.

528 Evolution Letters 1: 269-278.

529 Badiane A, Pérez i de Lanuza G, García-Custodio M del C, Carazo P \& Font E. 2017.

530 Colour patch size and measurement error using reflectance spectrophotometry. Methods in

$531 \quad$ Ecology and Evolution 8: 1585-1593.

532 Badiane A, Martin M, Meylan S, Richard M, Decencière Ferrandière B \& Le Galliard

533 JF. 2020. Male ultraviolet reflectance and female mating history influence female mate

534 choice and male mating success in a polyandrous lizard. Biological Journal of the Linnean

535 Society 130: 586-598.

536 Baird TA. 2013. Lizards and other reptiles as model systems for the study of contest

537 behaviour. In: Hardy IC, Briffa M, eds. Animal Contests., 258-286. 
Bartoń K. 2019. ‘MuMin’: Multi-model inference.

Bates D, Maechler M, Bolker B \& Walker S. 2015. Fitting linear mixed-effects models using lme4. Journal of statistical software 67: 1-48.

Bauwens D. 1987. Sex recognition by males of the lizard Lacerta vivipara: an introductory

$$
\text { study. Amphibia-Reptilia 8: 49-57. }
$$

Beani L \& Turillazzi S. 1999. Stripes display in hover-wasps (Vespidae: Stenogastrinae): A socially costly status badge. Animal Behaviour 57: 1233-1239.

Blumstein DT \& Daniel JC. 2007. Quantifying behavior the Jwatcher way.

Bonnaffé W, Martin M, Mugabo M, Meylan S \& Le Galliard J. 2018. Ontogenetic trajectories of body coloration reveal its function as a multicomponent nonsenescent signal. Ecology and Evolution 8: ece3.4369.

Bradbury JW \& Vehrencamp SL. 2011. Principles of animal communication. Sinauer Association Press Sunderland.

Carazo P \& Font E. 2014. 'Communication breakdown': The evolution of signal unreliability and deception. Animal Behaviour 87: 17-22.

Carazo P, Font E \& Desfilis E. 2008. Beyond 'nasty neighbours' and 'dear enemies'? Individual recognition by scent marks in a lizard (Podarcis hispanica). Animal Behaviour 76: $1953-1963$.

Carpenter GC. 1995. Modeling Dominance : the Influence of size, coloration, and experience on dominance relations in tree lizards (Urosaurus ornatus). Herpetological Monographs 9: 88-101.

Cote J, Le Galliard JF, Rossi JM \& Fitze PS. 2008. Environmentally induced changes in carotenoid-based coloration of female lizards: a comment on Vercken et al. Journal of Evolutionary Biology 21: 1165-1172.

Fitze PS, Le Galliard JF, Federici P, Richard M \& Clobert J. 2005. Conflict over 
563 multiple-partner mating between males and females of the polygynandrous common lizards.

564 Evolution 59: 2451-2459.

565 Fitze PS \& Le Galliard JF. 2008. Operational sex ratio, sexual conflict and the intensity of

566 sexual selection. Ecology Letters 11: 432-439.

567 Fitzpatrick S. 1998. Colour schemes for birds: Structural coloration and signals of quality in 568 feathers. Annales Zoologici Fennici 35: 67-77.

569 de Fraipont M, Colbert J, John-Alder H \& Meylan S. 2000. Increased pre-natal maternal

570 corticosterone promotes in common of offspring philopatry lizards Lacerta vivipara. Journal

571 of Animal Ecology 69: 404-413.

572 Le Galliard JF, Fitze PS, Ferrière R \& Clobert J. 2005. Sex ratio bias, male aggression,

573 and population collapse in lizards. Proceedings of the National Academy of Sciences 102:

$574 \quad 18231-18236$.

575 Grafen A. 1990. Biological signals as handicaps. Journal of Theoretical Biology 144: 517-

576546.

577 Guilford T \& Dawkins MS. 1995. What are conventional signals? Animal Behaviour 49:

$578 \quad 1689-1695$.

579 Heulin B. 1988. Observations sur l'organisation de la reproduction et sur les comportements

580 sexuels et agonistiques chez Lacerta vivipara. Vie et milieu 38: 177-187.

581 Higham JP. 2014. How does honest costly signaling work? Behavioral Ecology 25: 8-11.

582 Hurd PL. 1997. Is signalling of fighting ability costlier for weaker individuals? Journal of

583 Theoretical Biology 184: 83-88.

584 Hurd PL \& Enquist M. 2005. A strategic taxonomy of biological communication. Animal

585 Behaviour 70: 1155-1170.

586 Husak JF, Lappin KA, Fox SF \& Lemos-Espinal JA. 2006. Bite-Force Performance

587 Predicts Dominance in Male Venerable Collared Lizards (Crotaphytus antiquus). Copeia 
588

589

590

591

592

593

594

595

596

597

598

599

600

601

602

603

604

605

606

607

608

609

610

611 mates changes along successive matings in a lizard. Behavioural Processes 88: 149-154.

612 Lappin AK \& Husak JF. 2005. Weapon performance, not size, determines mating success

2006: $301-306$.

\section{Huyghe K, Vanhooydonck B, Scheers H, Molina-Borja M \& Van Damme R. 2005.}

Morphology, performance and fighting capacity in male lizards, Gallotia galloti. Functional Ecology 19: 800-807.

Johnstone RA \& Norris K. 1993. Badges of status and the cost of aggression. Behavioral Ecology and Sociobiology 32: 127:134.

Karsten KB, Andriamandimbiarisoa LN, Fox SF \& Raxworthy CJ. 2009. Sexual selection on body size and secondary sexual characters in 2 closely related, sympatric chameleons in Madagascar. Behavioral Ecology 20: 1079-1088.

Kemp DJ \& Grether GF. 2015. Integrating functional and evolutionary approaches to the study of color-based animal signals. In: Animal Signaling and Function: An Integrative Approach., 111-140.

Kemp DJ, Herberstein ME \& Grether GF. 2012. Unraveling the true complexity of costly color signaling. Behavioral Ecology 23: 233-236.

Kemp DJ \& Rutowski RL. 2007. Condition dependence, quantitative genetics, and the potential signal content of iridescent ultraviolet butterfly coloration. Evolution 61: 168-183.

Kurvers RHJM, Delhey K, Roberts ML \& Peters A. 2010. No consistent female preference for higher crown UV reflectance in Blue Tits Cyanistes caeruleus: A mate choice experiment. Ibis 152: 393-396.

Laloi D, Richard M, Lecomte J, Massot M \& Clobert J. 2004. Multiple paternity in clutches of common lizard Lacerta vivipara: Data from microsatellite markers. Molecular Ecology 13: 719-723.

Laloi D, Eizaguirre C, Fédérici P \& Massot M. 2011. Female choice for heterozygous 
613 and potential reproductive output in the collared lizard (Crotaphytus collaris). American

614 Naturalist 166: 426-436.

615 Lappin AK \& Jones MEH. 2014. Reliable quantification of bite-force performance requires

616 use of appropriate biting substrate and standardization of bite out-lever. The Journal of

617 Experimental Biology 217: 4303-4312.

618 Ligon RA \& McGraw KJ. 2016. Social costs enforce honesty of a dynamic signal of

619 motivation. Proceedings of the Royal Society B: Biological Sciences 283.

620 Lüdecke D, Makowski D, Waggoner P \& Patil I. 2020. Performance: Assessment of

621 regression models performance, CRAN, R package.

622 Maia R, Gruson H, Endler JA \& White TE. 2019. pavo 2: new tools for the spectral and 623 spatial analysis of colour in R. Methods in Ecology and Evolution 10: 1097-1107.

624 Martin M, Meylan S, Gomez D \& Le Galliard JF. 2013. Ultraviolet and carotenoid-based 625 coloration in the viviparous lizard Zootoca vivipara (Squamata: Lacertidae) in relation to age, 626 sex, and morphology. Biological Journal of the Linnean Society 110: 128-141.

627 Martin M, Meylan S, Perret S \& Le Galliard JF. 2015. UV coloration influences spatial 628 dominance but not agonistic behaviors in male wall lizards. Behavioral Ecology and 629 Sociobiology 69: 1483-1491.

630 Martin M, Meylan S, Haussy C, Decencière B, Perret S \& Le Galliard JF. 2016. UV

631 color determines the issue of conflicts but does not covary with individual quality in a lizard. 632 Behavioral Ecology 27: 262-270.

633 Martín J \& Forsman A. 1997. Social costs and development of nuptial coloration in male 634 Psammodromus algirus lizards : an experiment. Behavioral Ecology 10: 396-400.

635 Massot M, Clobert J, Pilorge T, Lecomte J \& Barbault R. 1992. Density dependence in 636 the common lizard: demographic consequences of a density manipulation. Ecology 73: 17426371756. 
638 Maynard Smith J \& Harper D. 2003. Animal signals. New York: Orford University Press.

639 Møller AP. 1987. Variation in badge size in male house sparrows Passer domesticus:

640 evidence for status signalling. Animal Behaviour 35: 1637-1644.

641 Molles LE \& Vehrencamp SL. 2001. Songbird cheaters pay a retaliation cost: Evidence for 642 auditory conventional signals. Proceedings of the Royal Society B: Biological Sciences 268: $643 \quad 2013-2019$.

644 Names G, Martin M, Badiane A \& Le Galliard JF. 2019. The relative importance of body 645 size and UV coloration in influencing male-male competition in a lacertid lizard. Behavioral 646 Ecology and Sociobiology 73: 98.

647 Pinheiro J, Bates D, DebRoy S, Sarkar D \& RCoreTeam. 2019. nlme: Linear and 648 nonlinear mixed effects models.

649 Poesel A, Peters A, Dabelsteen T, Darden SK \& Delhey K. 2007. Territorial responses of 650 male blue tits, Cyanistes caeruleus, to UV-manipulated neighbours. Journal of Ornithology 651 148: $179-187$.

652 Qvarnstrom A. 1997. Experimentally increased badge size increases male competition and 653 reduces male parental care in the collared flycatcher. Proceedings of the Royal Society B:

654 Biological Sciences 264: 1225-1231.

655 R Development Core Team. 2017. R: A language and environment for statistical computing.

656 Rémy A, Grégoire A, Perret P \& Doutrelant C. 2010. Mediating male-male interactions:

657 The role of the UV blue crest coloration in blue tits. Behavioral Ecology and Sociobiology 64: $658 \quad 1839-1847$.

659 Rohwer S \& Rohwer FC. 1978. Status signalling in Harris Sparrows. Animal Behaviour 26: $660 \quad 1012-1022$.

661 Roulin A. 2016. Condition-dependence, pleiotropy and the handicap principle of sexual 662 selection in melanin-based colouration. Biological Reviews 91: 328-348. 
663 Rozen-Rechels D, Badiane A, Agostini S, Meylan S \& Le Galliard J. 2020. Water

664 restriction induces behavioral fight but impairs thermoregulation in a dry-skinned ectotherm.

665 Oikos 129: 572-584.

666 Rozen-Rechels D, Dupoué A, Meylan S, Decencière B, Guingand S \& Le Galliard JF.

667 2018. Water restriction in viviparous lizards causes transgenerational effects on behavioral 668 anxiety and immediate effects on exploration behavior. Behavioral Ecology and Sociobiology 66972.

670 San-Jose LM, Huyghe K, Schuerch J \& Fitze PS. 2017. More melanized males bite

671 stronger but run slower: potential performance trade-offs related to melanin-based coloration.

672 Biological Journal of the Linnean Society 122: 184-196.

673 San-Jose LM \& Roulin A. 2018. Toward understanding the repeated occurrence of

674 associations between melanin-based coloration and multiple phenotypes. The American

675 Naturalist 192: 111-130.

676 Schielzeth H. 2010. Simple means to improve the interpretability of regression coefficients.

677 Methods in Ecology and Evolution 1: 103-113.

678 Searcy W \& Nowicki S. 2005. The evolution of animal communication: reliability and

679 deception in signaling systems.

680 Shawkey MD \& D'Alba L. 2017. Interactions between colour-producing mechanisms and

681 their effects on the integumentary colour palette. Philosophical Transactions of the Royal

682 Society B: Biological Sciences 372: 20160536.

683 Stapley J \& Whiting MJ. 2006. Ultraviolet signals fighting ability in a lizard. Biology

684 Letters 2: 169-172.

685 Svensson PA \& Wong BBM. 2011. Carotenoid-based signals in behavioural ecology: A

686 review. Behaviour 148: 131-189.

687 Tibbetts EA. 2014. The evolution of honest communication: Integrating social and 
688 physiological costs of ornamentation. Integrative and Comparative Biology 54: 578-590.

689 Tibbetts EA \& Izzo A. 2010. Social punishment of dishonest signalers caused by mismatch 690 between signal and behavior. Current Biology 20: 1637-1640.

691 Vehrencamp SL. 2001. Is song-type matching a conventional signal of aggressive intentions?

692 Proceedings of the Royal Society B: Biological Sciences 268: 1637-1642.

693 Weaver RJ, Koch RE \& Hill GE. 2017. What maintains signal honesty in animal colour 694 displays used in mate choice? Philosophical Transactions of the Royal Society of London B: 695 Biological Sciences 372: 20160343.

696 Webster MS, Ligon RA \& Leighton GM. 2018. Social costs are an underappreciated force 697 for honest signalling in animal aggregations. Animal Behaviour 143: 167-176.

698 White TE. 2020. Structural colours reflect individual quality : a meta-analysis. Biology 699 Letters 16: 20200001.

700 Whiting MJ, Nagy K a \& Bateman PW. 2003. Evolution and maintenance of social status701 signaling badges. In: Lizard social behavior., 47-82.

702 Wilson RS \& Angilletta MJ. 2015. Dishonest signaling during aggressive interactions:

703 Theory and Empirical Evidence. In: Animal Signaling and Function: An Integrative 704 Approach., 205-227.

705 Zahavi A. 1975. Mate selection - A selection for a handicap. Journal of Theoretical Biology 706 53: 205-214. 


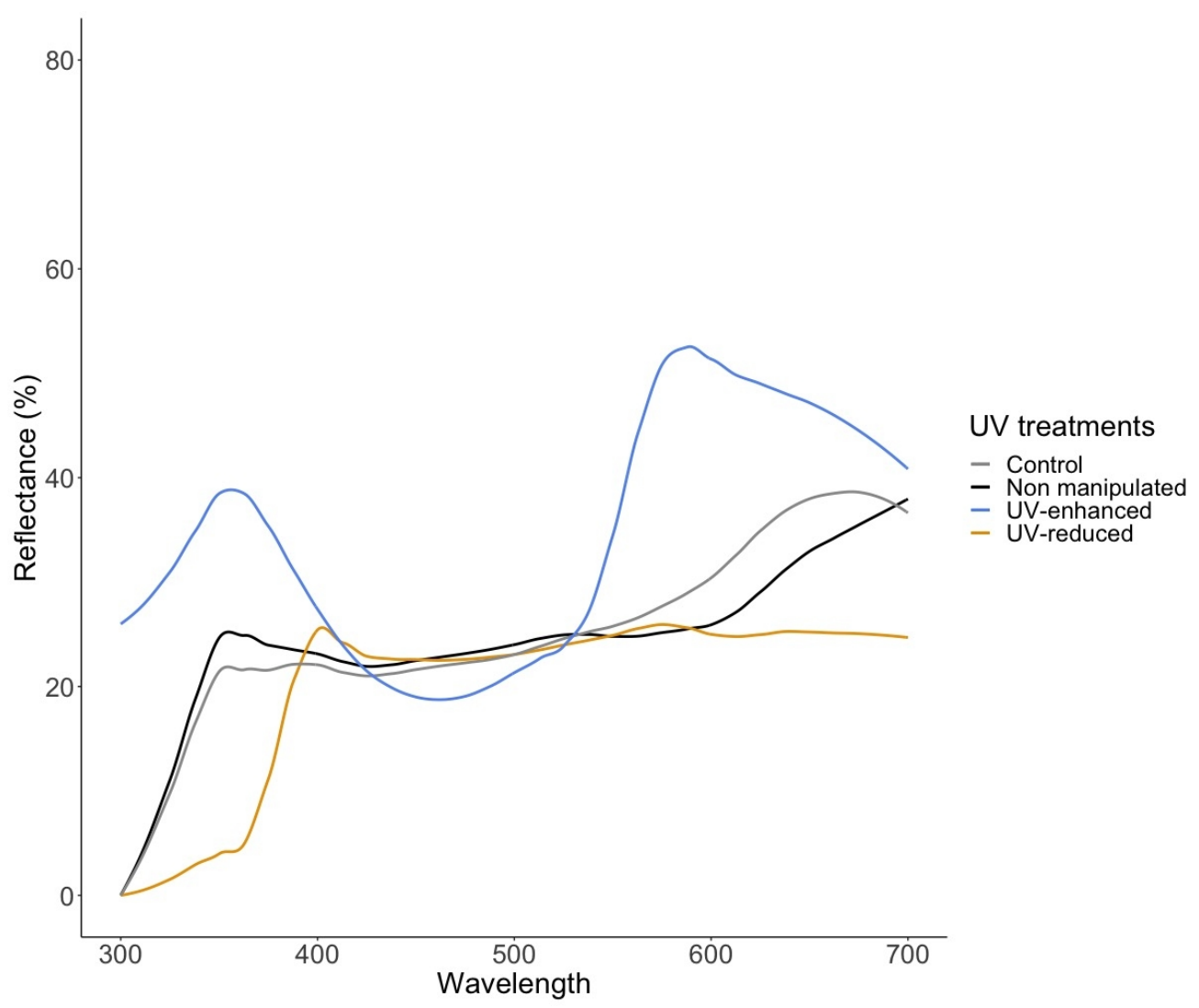

Reflectance spectra resulting from the different UV treatments of our experimental UV treatments applied on a single individual so that the spectral variations represented are only due to the experimental treatments.

Small cheaters were UV-enhanced using a light orange marker pen. Small honest males were not manipulated. Large cheaters were UV-reduced using a mix of UV-blocking inorganic agents and a fat solution. Large honest males were treated with a fat solution only.

\section{$423 \times 352 \mathrm{~mm}(72 \times 72 \mathrm{DPI})$}



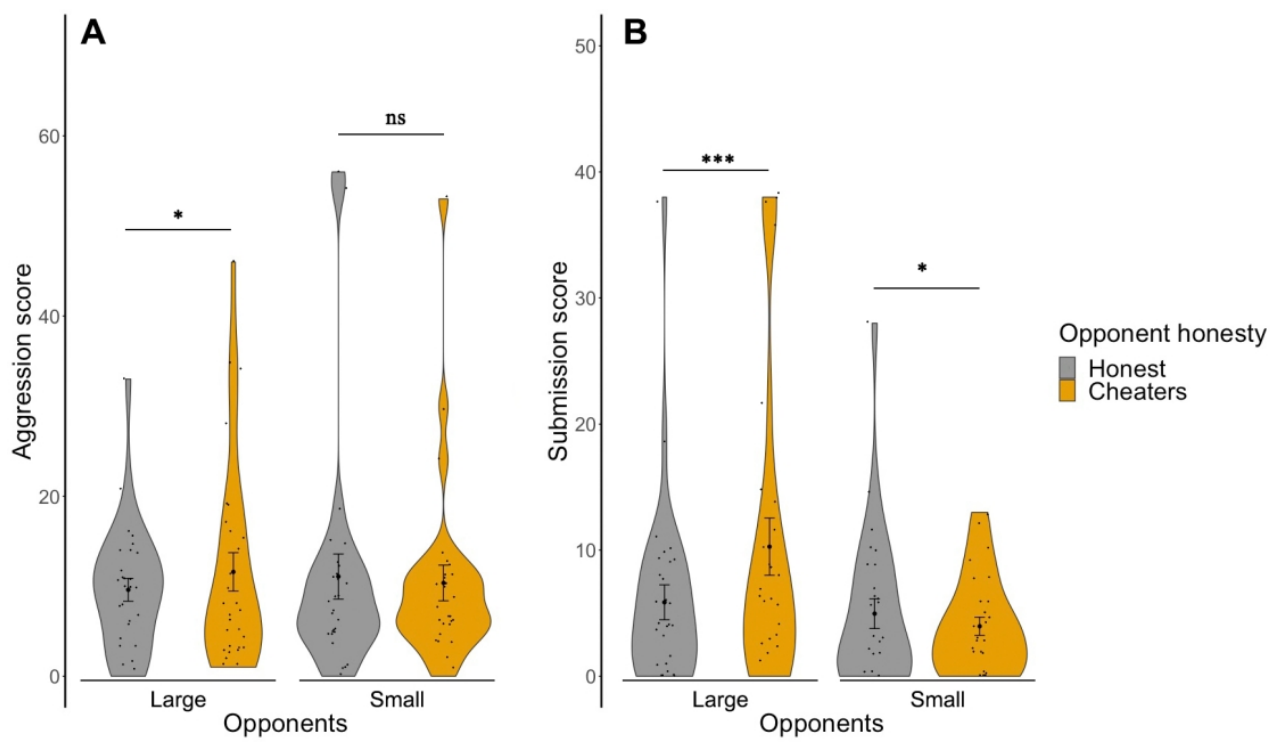

Violin plots including the mean and standard errors of the aggression score $(A)$ and the submission score (B) of focal males according the opponent body size and UV treatment. Aggression and submission scores were calculated by adding the aggressive and submissive behaviours, respectively, weighted by their coefficient (coef.1 from table 1). UV signals were reduced in large cheaters but enhanced in small cheaters. Levels of significance are indicated $(\mathrm{p}<0.05 *, \mathrm{p}<0.01, * *, \mathrm{p}<0.001 * * *)$.

$625 \times 352 \mathrm{~mm}(72 \times 72 \mathrm{DPI})$ 
1 Table 1: List and descriptions of the different behaviours displayed by male Zootoca vivipara 2 and their associated coefficient used to calculate scores. Coef.1 corresponds to the first set of 3 coefficients that we assigned to the behaviours and consider as the most realistic ranking.

4 Coef.2 and Coef. 3 are two additional sets of coefficients that vary slightly from Coef. 1 to 5 examine how coefficient assignment affect our results.

6

\begin{tabular}{|lllccc|}
\hline Scores & Behaviours & Description & Coef.1 & Coef.2 & Coef.3 \\
Aggression score & Approach & Reduce distance with rival & 1 & 1 & 1 \\
& Chase & Quickly follows fleeing rival & 2 & 2 & 2 \\
& Lunge & Hits rival with closed mouth & 3 & 3 & 3 \\
& Retaliation & Lunge in response to rival approach or lunge & 3 & 3 & 3 \\
& Bite & Holds rival for $<2$ s & 4 & 3 & 4 \\
& Bite hold & Holds rival for $>2$ s & 5 & 3 & 4 \\
Submission score & Tail wagging & Wagging movements of the tail & 1 & 1 & 1 \\
& Burry & Number of times a lizard burry itself into the soil substrate & 2 & 1 & 2 \\
& Escape & Rapid movement away from the rival & 3 & 1 & 2 \\
& Basking duration & Time spent basking on the wooden spot & - & - & - \\
& Wall-scratching & Time spent scratching the walls of the arena & - & - & - \\
& duration & & & & \\
\hline
\end{tabular}

7

8 
The role of social costs as a mechanism enforcing the honesty of ultraviolet signals in a lizard

\section{Supplementary information S1 - Social costs on dishonest UV signals}

2

3 Test statistics resulting from our models performed to investigate whether social costs are

4 associated with signal honesty. Estimates \pm standard error and the p-value of each predictor

5 are indicated. These models took the form response $\sim$ opponent size * opponent honesty +

6 bite force + random intercept factors. Random factors were always the ID of focal males and

7 trial order. The term 'interaction' means the two-way interaction between 'opponent size' and

8 'opponent honesty'. Levels of significance are indicated $(*<0.05, * *<0.01, * * *<0.001)$.

10 Table S1. Coefficient for each predictor and response variable.

\begin{tabular}{|ccccc|}
\hline Predictors & Aggression score & Submission score & Basking duration & $\begin{array}{c}\text { Wall-scratching } \\
\text { duration }\end{array}$ \\
\hline \multirow{2}{*}{ Bite Force } & $0.18 \pm 0.11$ & $-0.05 \pm 0.14$ & $0.12 \pm 0.12$ & $0.12 \pm 0.15$ \\
& $\mathrm{P}=0.101$ & $\mathrm{P}=0.710$ & $\mathrm{P}=0.334$ & $\mathrm{P}=0.418$ \\
\hline \multirow{2}{*}{ Opponent honesty } & $0.20 \pm 0.08$ & $0.51 \pm 0.10$ & $-0.39 \pm 0.23$ & $-0.17 \pm 0.19$ \\
& $\mathrm{P}=0.012^{*}$ & $\mathrm{P}<0.001^{* * *}$ & $\mathrm{P}=0.100$ & $\mathrm{P}=0.385$ \\
\hline \multirow{2}{*}{ Opponent size } & $0.22 \pm 0.09$ & $-0.22 \pm 0.12$ & $-0.29 \pm 0.24$ & $-0.16 \pm 0.20$ \\
& $\mathrm{P}=0.009^{* *}$ & $\mathrm{P}=0.055$ & $\mathrm{P}=0.218$ & $\mathrm{P}=0.411$ \\
\hline \multirow{2}{*}{ Interaction } & $-0.33 \pm 0.12$ & $-0.73 \pm 0.16$ & $0.60 \pm 0.33$ & $0.19 \pm 0.28$ \\
& $\mathrm{P}=0.004^{* *}$ & $\mathrm{P}<0.001^{* * *}$ & $\mathrm{P}=0.077$ & $\mathrm{P}=0.499$ \\
\hline
\end{tabular}

11

\section{Supplementary information S2 - Contest outcome in control interactions}

15 Results of the model selection procedure taking into account only the interactions between

16 focal males and control opponents and excluding manipulated opponents. Table S2 provides

17 the best models $(\triangle \mathrm{AICc}<2)$ and the null model for each response variable obtained from our

18 model selection procedure involving a total of 64 models. We also provide the AICc score, 
The role of social costs as a mechanism enforcing the honesty of ultraviolet signals in a lizard

19 the $\triangle \mathrm{AICc}$, and the weight of each one of the best models. Table S3 summarises the

20 conditional model averaging and indicates the estimates \pm the adjusted standard error and the

$21 p$ value of each predictor. When the predictor Null is indicated, it corresponds to the null

22 model in which no predictors were added. These models were in the form response

23 predictors + random intercept factors. Random factors were always ID of the focal male and

24 trial order.

26 Table S2. Best models for each response variable.

\begin{tabular}{|c|c|c|c|c|}
\hline Response & Predictors & $\mathrm{AICc}$ & $\triangle \mathrm{AICc}$ & Weight \\
\hline \multirow{5}{*}{$\begin{array}{l}\text { Aggression } \\
\text { score }\end{array}$} & Bite Force & 374.07 & 0.00 & 0.16 \\
\hline & Bite Force $+\mathrm{UV}_{\text {chroma }}$ & 375.30 & 1.23 & 0.09 \\
\hline & Bite Force + Opponent $U V_{\text {intensity }}$ & 375.61 & 1.44 & 0.08 \\
\hline & Bite Force $+U_{\text {intensity }}$ & 375.71 & 1.64 & 0.07 \\
\hline & Null & 377.81 & 3.74 & 0.02 \\
\hline \multirow{3}{*}{$\begin{array}{l}\text { Submission } \\
\text { score }\end{array}$} & Opponent $\mathrm{UV}_{\text {intensity }}$ & 348.57 & 0.00 & 0.23 \\
\hline & Opponent $\mathrm{UV}_{\text {intensity }}+\mathrm{UV}_{\text {intensity }}$ & 350.36 & 1.78 & 0.09 \\
\hline & Null & 354.55 & 5.98 & 0.01 \\
\hline \multirow{8}{*}{$\begin{array}{l}\text { Basking } \\
\text { duration }\end{array}$} & Opponent $\mathrm{UV}_{\text {chroma }}+$ Bite Force & 154.89 & 0.00 & 0.09 \\
\hline & Opponent $\mathrm{UV}_{\text {chroma }}+$ Bite Force $+\mathrm{UV}_{\text {intensity }}$ & 155.62 & 0.73 & 0.06 \\
\hline & Bite Force & 155.72 & 0.83 & 0.06 \\
\hline & Bite Force + Opponent Body Size & 156.16 & 1.28 & 0.05 \\
\hline & Bite Force $+\mathrm{UV}_{\text {intensity }}$ & 156.24 & 1.35 & 0.05 \\
\hline & Bite Force + Opponent Body Size $+U V_{\text {intensity }}$ & 156.77 & 1.89 & 0.04 \\
\hline & Opponent $\mathrm{UV}_{\text {chroma }}$ & 156.85 & 1.96 & 0.03 \\
\hline & Null & 157.20 & 2.32 & 0.03 \\
\hline \multirow{4}{*}{$\begin{array}{c}\text { Wall- } \\
\text { scratching } \\
\text { duration }\end{array}$} & $\mathrm{UV}_{\text {intensity }}$ & 136.69 & 0.00 & 0.18 \\
\hline & Opponent Body Size $+\mathrm{UV}_{\text {intensity }}$ & 138.05 & 1.36 & 0.09 \\
\hline & $\mathrm{UV}_{\text {chroma }}+\mathrm{UV}_{\text {intensity }}$ & 138.27 & 1.58 & 0.08 \\
\hline & Null & 140.44 & 3.75 & 0.03 \\
\hline
\end{tabular}

27

28 Table S3. Conditional model-averaged coefficient ( $\beta \pm \mathrm{se}), p$-value, and sum of weights (sw)

29 for each predictor and response variable. 
The role of social costs as a mechanism enforcing the honesty of ultraviolet signals in a lizard

\begin{tabular}{|c|c|c|c|c|}
\hline Predictors & Aggression score & Submission score & Basking duration & $\begin{array}{c}\text { Wall-scratching } \\
\text { duration }\end{array}$ \\
\hline \multirow{3}{*}{$\mathrm{UV}_{\text {chroma }}$} & $0.15 \pm 0.12$ & $-0.11 \pm 0.23$ & $0.12 \pm 0.17$ & $-0.21 \pm 0.17$ \\
\hline & $P=0.249$ & $P=0.626$ & $P=0.503$ & $\mathrm{P}=0.218$ \\
\hline & $\mathrm{sw}=0.36$ & $\mathrm{sw}=0.23$ & $\mathrm{sW}=0.26$ & $\mathrm{sw}=0.30$ \\
\hline \multirow{3}{*}{$\mathrm{UV}_{\text {intensity }}$} & $0.08 \pm 0.11$ & $0.24 \pm 0.23$ & $-0.22 \pm 0.17$ & $0.47 \pm 0.17$ \\
\hline & $\mathrm{P}=0.452$ & $\mathrm{P}=0.297$ & $P=0.183$ & $\mathrm{P}=0.006^{* *}$ \\
\hline & $\mathrm{sW}=0.27$ & $\mathrm{sw}=0.29$ & $\mathrm{sw}=0.43$ & $\mathrm{sW}=0.87$ \\
\hline \multirow{3}{*}{ Opponent $\mathrm{UV}_{\text {chroma }}$} & $0.04 \pm 0.14$ & $-0.04 \pm 0.15$ & $-0.19 \pm 0.14$ & $0.08 \pm 0.20$ \\
\hline & $\mathrm{P}=0.771$ & $\mathrm{P}=0.818$ & $\mathrm{P}=0.186$ & $P=0.682$ \\
\hline & $\mathrm{sW}=0.23$ & $\mathrm{sw}=0.23$ & $\mathrm{sw}=0.47$ & $\mathrm{sW}=0.25$ \\
\hline \multirow{3}{*}{ Opponent $\mathrm{UV}_{\text {intensity }}$} & $0.13 \pm 0.14$ & $0.26 \pm 0.12$ & $-0.06 \pm 0.14$ & $0.05 \pm 0.11$ \\
\hline & $P=0.357$ & $\mathrm{P}=0.038^{*}$ & $P=0.652$ & $\mathrm{P}=0.641$ \\
\hline & $\mathrm{sw}=0.30$ & $\mathrm{sw}=0.94$ & $\mathrm{sw}=0.23$ & $\mathrm{sw}=0.22$ \\
\hline \multirow{3}{*}{ Opponent size } & $0.11 \pm 0.28$ & $-0.24 \pm 0.20$ & $-0.19 \pm 0.31$ & $-0.34 \pm 0.25$ \\
\hline & $P=0.703$ & $P=0.239$ & $\mathrm{P}=0.554$ & $P=0.167$ \\
\hline & $\mathrm{sW}=0.23$ & $\mathrm{sw}=0.25$ & $\mathrm{sw}=0.33$ & $\mathrm{sw}=0.32$ \\
\hline \multirow{3}{*}{ Bite Force } & $0.29 \pm 0.11$ & $-0.06 \pm 0.24$ & $0.31 \pm 0.16$ & $0 ; 04 \pm 017$ \\
\hline & $\mathrm{P}=0.010^{*}$ & $P=0.812$ & $P=0.059$ & $P=0.838$ \\
\hline & $\mathrm{sW}=0.84$ & $\mathrm{sw}=0.23$ & $\mathrm{sw}=0.66$ & $\mathrm{sw}=0.22$ \\
\hline
\end{tabular}

30 